\title{
Efficiency Optimization of Asynchronism Motor Based on a Novel Reaching Law
}

\author{
Jing-li Miao \\ School of Information \& Electric Engineering, Hebei University of Engineering, Handan, China \\ Email: miaojingli@sina.com \\ Yuan Huang \\ School of Information \& Electric Engineering, Hebei University of Engineering, Handan, China \\ Email:757918272@qq.com
}

\begin{abstract}
To satisfy with the high-power control of the asynchronism motor control drive system, this paper devised a novel reaching law of sliding mode variable structure control strategy and analysed this control strategy for vector control system of asynchronism motor and the high-frequency chattering phenomenon in traditional sliding mode controllers. The simulation results demonstrate that the control strategy can ensure rapid dynamic speed response during the efficiency optimization at low loads and decrease chattering phenomenon effectively, greatly improve the robustness of asynchronism motor and improve control quality.
\end{abstract}

Index Terms-asynchronism motor, sliding mode variable structure, chattering, efficiency optimization

\section{INTRODUCTION}

Because of asynchronous motors' simple structure low cost、 reliable operation, durability , easy maintenance and better operating characteristics, makes it widely used in industrial、agricultural and civilian fields ${ }^{[1]}$. Since the 1990s, the induction motor efficiency optimization control problem has attracted wide attention ${ }^{[2-7]}$, and to reduce the rotor flux is used to improve the operational efficiency of asynchronous motor with light-loading, but as we all know, asynchronism motor is a high order、 nonlinear、strong coupling multivariable system,reduce the rotor flux will lead to slow dynamic response speed of the drive system, because of its simple physical implementation and strong anti-interference ability, sliding mode variable structure control can avoid the impact on the dynamic performance of motor by load or parameter changes, and it is widely used in asynchronous motor control by domestic and foreign scholars in recent years ${ }^{[8-11]}$. However, the conventional sliding mode variable structure control uses the switch function in its control method, this will inevitably lead to back and forth across both sides of the sliding mode surface when state trajectory reaches the sliding mode surface, and it is difficult to strictly slide to equilibrium point along the sliding mode surface, causing the control signal chattering. In this paper, asynchronism motor sliding mode variable structure control method based on a novel reaching law is designed for the efficiency optimization control of asynchronism motor, and stability analysis and simulation test are performed to compare with the simulation results of sliding mode controller based on the conventional reaching law function ${ }^{[12]}$.

\section{MATHEMATICAL MODEL OF THE ASYNCHRONISM MOTOR}

In the rotor field oriented synchronous rotating coordinate system, the mathematical model equation ${ }^{[13]}$ of asynchronous motor speed and rotor flux as follows:

$$
\begin{gathered}
\frac{d \omega_{r}}{d t}=c_{t} \varphi_{r} i_{s q}-\frac{T_{L}}{J} \\
\frac{d \varphi_{r}}{d t}=-\frac{R_{r}}{L_{r}} \varphi_{r}+\frac{R_{r} L_{m}}{L_{r}} i_{s d}
\end{gathered}
$$

Optimal rotor flux of asynchronous motor is ${ }^{[13]}$ :

$$
\psi_{\text {rop }}={\sqrt{\frac{T_{e}}{n_{p}}}}_{4}^{4} \sqrt{L_{r}^{2}+\frac{R_{r} L_{m}^{2}}{R_{s}}}
$$

Among them, $c_{t}=\frac{n_{p} L_{m}}{J L_{r}} ; \varphi_{r}$-rotor winding flux; $L_{s}$ is stator inductance; $L_{r}$ is rotor inductance; $L_{m}$ is mutual inductance between stator and rotor; $R_{s}$ is stator resistance; $R_{r}$ is rotor resistance; $T_{e}$ is electromagnetic torque of the motor; $i_{s d}, i_{s q}$ represent d-axis component and q-axis component of stator current, respectively; $L_{r}$ represents rotor winding inductance; $\omega_{r}$ represents rotor 
electric angular velocity; $n_{p}$ is pole-pair number of the motor; $T_{L}$ represents load torque; $J$ is rotary inertia.

\section{SLIDING MODE CONTROLLER DESIGN}

\section{A. Traditional Exponential Reaching Law}

Traditional exponential reaching law is

-

$$
\dot{s}=-k s-\varepsilon \operatorname{sgn}(s) \quad \varepsilon>0, k>0
$$

In exponential reaching law, the reaching speed of reaching law can not well reflect the current state of the system and the sliding mode surface, Reaching law parameters can not change based on the changes of the current state of the system, which lead to the above reaching law sliding mode controller application be restricted because of the exist of the system chattering. In order to improve the dynamic quality of the asynchronism motor speed control system, in this paper, a novel reaching law is proposed based on the pure exponential reaching law, which is different from the traditional reaching law, it does not contain a switching function, which helps the chattering be further reduced.

\section{B. Novel Reaching Law}

In order to accelerate the convergence and make the system state reach the sliding mode surface quickly, a reaching law of variable parameters is used based on pure exponential reaching law. Improved reaching law is:

$$
\dot{S_{i}}=-\varepsilon_{i}\left(k_{i}^{\left|s_{i}\right|}-1\right) s_{i}
$$

In the formula, $\varepsilon_{i}>0, k_{i}>1, i=1,2$,

The novel reaching law sliding mode control differs from the traditional exponential reaching law sliding mode control in that: it uses a different reaching law function, and the reaching speed can well reflect the current state of the system and the distance to the sliding mode surface, which make the approach speed be adjusted with the size of $|\mathrm{s}|$. When $|\mathrm{s}|$ is large, it shows that the system state variable running track is far from the sliding mode surface, the reaching speed should be increased; when $|s|$ is small, it shows that the system state variable running track is close to the sliding mode surface, the reaching speed should be reduced, thus reducing the chattering, which enable the system to reach the sliding mode surface smoothly.

\section{Sliding Mode Controller Design for Asynchronism Motor}

In order to make the speed stably track its given value when motor is in efficiency optimal operation, take the state variables as asynchronism motor speed and rotor flux , therefore, select the linear sliding mode surface as follows:

$$
\begin{aligned}
& s_{1}=c_{1} e_{1}, e_{1}=\omega_{r e f}-\omega_{r} \\
& s_{2}=c_{2} e_{2}, e_{2}=\varphi_{r e f}-\varphi_{r}
\end{aligned}
$$

In the formula $, c_{1}>0, c_{2}>0, \omega_{\text {ref }}$ - given angular velocity $; \omega_{r}$ - actual angular velocity ; $\varphi_{\text {ref }}$ given rotor flux ; $\varphi_{r}$ - actual rotor flux .

By formula (1) and (6) we get:

$\dot{s_{1}}=c_{1} \dot{e}_{1}=c_{1}\left(\dot{\omega}_{r e f}-\dot{\omega}_{r}\right)=c_{1}\left(\dot{\omega}_{r e f}-c_{t} \varphi_{r} i_{s q}-\frac{T_{L}}{J}\right)$

By formula (2) and (7) we get:

$\dot{s_{2}}=c_{2} \dot{e}_{2}=c_{2}\left(\dot{\varphi_{r e f}}-\dot{\varphi}_{r}\right)=c_{2}\left(\dot{\varphi_{r e f}}+\frac{R_{r}}{L_{r}} \varphi_{r}-\frac{R_{r} L_{m}}{L_{r}} i_{s d}\right)$

By formula (5) and (8) we get:

$i_{s q}=\frac{1}{c_{1} c_{t} \varphi_{r}}\left(c_{1} \dot{\omega_{r e f}}+c_{1} \frac{T_{L}}{J}+\varepsilon_{1} s_{1}\left(k_{1}^{\left|s_{1}\right|}-1\right)\right)$

By formula (5) and (9) we get:

$i_{s d}=\frac{1}{c_{2} R_{r} L_{m}}\left(L_{r} c_{2} \dot{\varphi_{r e f}}+c_{2} R_{r} \dot{\varphi_{r}}+L_{r} \varepsilon_{2} s_{2}\left(k_{2}^{\left|s_{2}\right|}-1\right)\right)$

\section{STABILITY ANALYSIS}

Theorem: the sliding mode controller obtained by formula (10) and (11) can satisfy the sliding mode reachability conditions .

Proof : take the Lyapunov function as follow:

$$
V=\frac{1}{2} s^{T} S
$$

Where $s=\left[s_{1}, s_{2}\right]^{T}$, then

$$
\begin{aligned}
\dot{V}= & \dot{s}=s_{1} \dot{s_{1}}+s_{2} \dot{s_{2}} \\
& =s_{1}\left(-\varepsilon_{1}\left(k_{1}^{\left|s_{1}\right|}-1\right) s_{1}\right)+s_{2}\left(-\varepsilon_{2}\left(k_{2}^{\left|s_{2}\right|}-1\right) s_{2}\right) \\
& =-\varepsilon_{1}\left(k_{1}^{\left|s_{1}\right|}-1\right) s_{1}^{2}-\varepsilon_{2}\left(k_{2}^{\left|s_{2}\right|}-1\right) s_{2}^{2}
\end{aligned}
$$

This can be drawn, when $s_{1}, s_{2} \neq 0, \dot{V}<0$, it can satisfy the sliding mode reachability conditions, namely the speed and rotor flux can track their given value.

\section{SIMULATION RESULTS AND ANALYSIS}

In order to verify the control effects of the new reaching law sliding mode variable structure controller on asynchronism motor when it is in efficiency optimal operation, this paper uses the asynchronous motor control system simulation model which is showed in figure 1, and adopts Matlab software for the simulation analysis on the system.

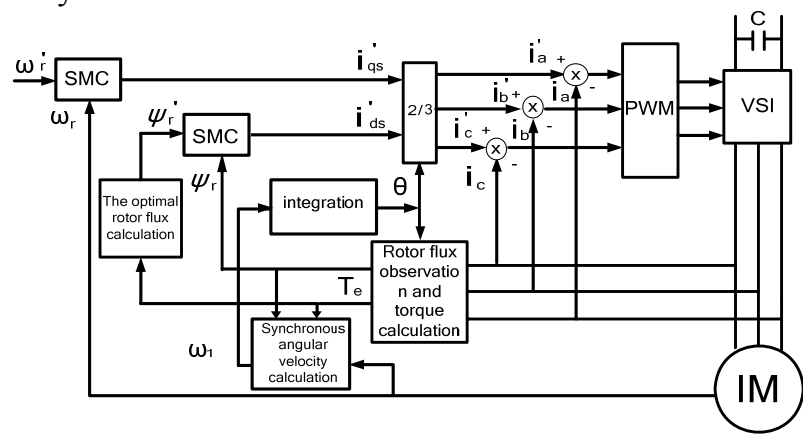

Fig. 1 Simulation block diagram of asynchronous motor control efficiency optimization control system 
The asynchronous motor parameters of the simulation are set as follows: rotor winding resistance $R_{r}=1.5 \quad \Omega \quad$,stator winding resistance $R_{s}=1.83 \quad \Omega \quad$,stator winding inductance $L_{s}=0.082 \mathrm{H}$,rotor winding inductance $L_{r}=0.082 H$,mutual inductance between stator and rotor $L_{m}=0.079 \mathrm{H}$, rotary inertia $J=0.058 \mathrm{~kg} . \mathrm{m}^{2}$, pole-pair number $n_{p}=2$. ODE method is adopted for solving, take simulation step as 0.0002 , the controller parameters of the simulation are : $\mathrm{k} 1=5, \mathrm{k} 2=5, \mathrm{c} 1=1, \mathrm{c} 2=1, \varepsilon 1=12, \varepsilon 2=12$ 。

The discussions in this paper are based on the speed control subsystem, the rotor flux at starting in simulation is given for $0.8 \mathrm{~Wb}$, the load torque is $5 \mathrm{~N} \cdot \mathrm{m}$, the system given speed is $700 \mathrm{r} / \mathrm{min}$, using efficiency optimization algorithm when simulation time is $1 \mathrm{~s}$, the load-mutation is $11 \mathrm{~N} \cdot \mathrm{m}$ when simulation time is $1.5 \mathrm{~s}$, the given mutation of motor speed is $450 \mathrm{r} / \mathrm{min}$ at $2 \mathrm{~s}$, the simulation time lasts 3 s. Figure 2 shows the speed dynamic response curves with two control schemes, figure 3 shows the stator current curve with the proposed control scheme, figure 4 shows the q-axis component of stator current output by controller with the proposed control scheme, figure 5 shows the q-axis component of stator current output by controller when using the traditional reaching law sliding mode variable structure control (SMC).

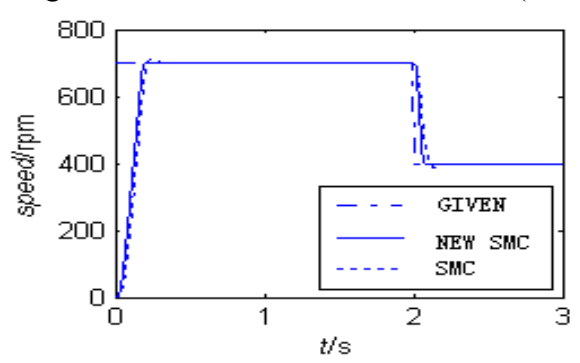

Fig. 2 Speed response waveform

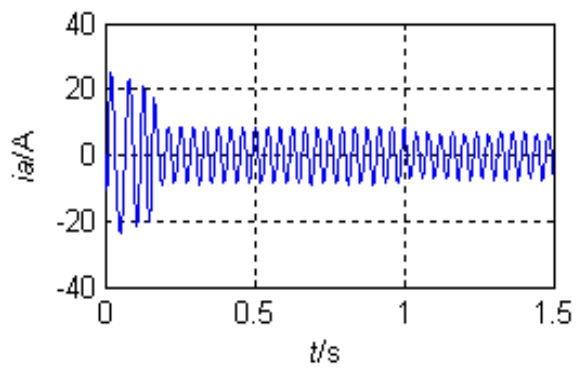

Fig. 3 The stator current curve when using the novel reaching law

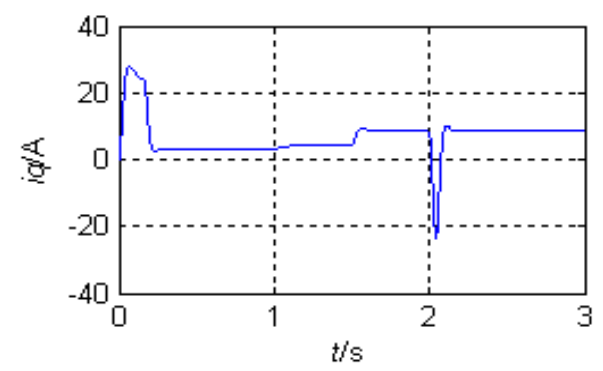

Fig. 4 Q-axis component of the stator current when using the novel

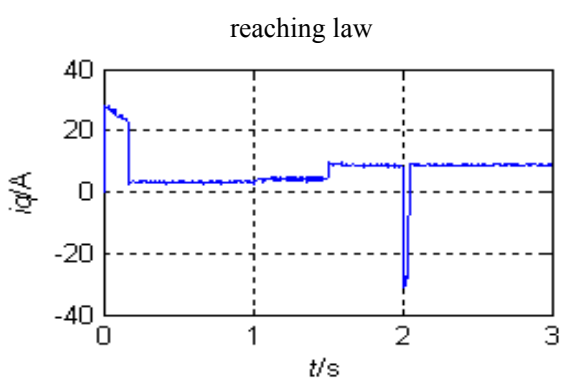

Fig. 5 Q-axis component of the stator current when using the traditional reaching law

It can be seen from figure 2, using the proposed control strategy, the speed can track the changes of given value quickly within $0.16 \mathrm{~s}$ in starting of the motor, and there is no obvious overshoot, and the changes of the speed given value do not bring obvious overshoot, it shows that the system has good speed dynamic response characteristics. When the motor is changed to efficiency optimal operation and the motor speed is constant but the load torque changes, the speed of the motor is essentially the same, no obvious chattering, this shows the system has good robustness. Figure 3 shows that the stator current is significantly reduced when using motor efficiency optimization, when using the proposed control scheme, the stator current sine is better and the torque ripple is smaller. The comparison between figure 4 and figure 5 shows that the chatting of the q-axis component of stator current output by controller is significantly reduced when using the proposed scheme in this paper. When using the traditional reaching law controller, the q-axis component of stator current output by controller exists significant chatting.

\section{CONCLUSION}

In this paper, a novel reaching law sliding mode variable structure controller in the control of asynchronism motor efficiency optimization running process is devised by the analysis of the traditional reaching law, it has realized the speed tracking and efficiency optimization control. The reaching law parameters can change according to the changes of the current system state, and does not contain the switching function terms, which make the chattering can be further reduced, thereby improving the control performance of the system. The simulation results show that the proposed controller improves the speed dynamic response speed and reduces the chatting of the control quantity, and has good robustness.

\section{ACKNOWLEDGMENT}

This paper is supported by Science and Technology Project of Hebei Province (No.12213912D).

\section{REFERENCES}

[1] Bo-shi Chen. "Electrical Towage Automatic Control Systems", Mechanical Industry Press, 2003.

[2] FLEMMING Abrahamser. "Energy optimal control of induction motor drive", Aalborg University: Institute of Energy Technology, 2000. 
[3] Slobodan N Vukosavic, Levi E. "Robust DSP- based efficiency optimization of a variable speed induction motor drive", IEEE Transactions on Industrial Electronics, vol. 50, pp. 560-570, 2003.

[4] Ta C M, Hori Y. "Convergence improvement of efficiency-optimization control of induction motor drives", IEEE Transactions on Industry Applications, vol. 37, pp. 1746-1753, 2001.

[5] Peter Mutschler, Emad Abdelkarim, Mahrous Ahmed, Mohamed Orabi. "Fuzzy logic speed controller of 3-Phase induction motors for efficiency improvement", Journal of power electronics, vol. 12, pp. 305-316, 2012.

[6] Durval de Almeida Souza, Wilson C. P. de Aragao Filho, Gilberto Costa DrumondSousa. Adaptive fuzzy controller for efficiency optimization of induction motors. IEEE Transactions on Industrial Electronics, vol. 54, pp. 2157-2164, 2007.

[7] Hui-fang Kong, Guo-qing Ren, Ji-zhu He, Ben-xian Xiao. "The Application of Fuzzy Neural Network in Fault Self-diagnosis System of Automatic Transmission", Journal of Software,vol. 6, pp. 209-216, 2011.

[8] Guo-hua Li, Ji-qiang Wang. "The new asynchronism motor sliding mode variable structure speed observer research”,Electric Drive, vol. 41, pp. 11-14, 2011.

[9] Wai R J, Lin C M, Hsu C F. "Adaptive fuzzy sliding mode control for electrical servo drive", Fuzzy Sets and Systems, vol. 143, pp. 295 310, 2004.

[10] Kim S M, Han W Y, Kim S J. "Design of a new adaptive sliding mode observer for sensorless induction motor drive", Electric Power Systems Research, vol. 70, pp. 16 22, 2004.

[11] M. Behloul, M.S. Nait-Said, S. Drid. "Speed-sensorless sliding-mode direct torque control of induction motors", Electromotion, vol. 18, pp. 29-36, 2011.
[12] Feng Gao. "Applications of Matlab in Mathematical Analysis", Journal of Software, vol. 6, pp. 1230-1234, 2011.

[13] Jing-li Miao, Hua-de Li, Guang-da Hu, Ren-tao Zhao. "Asynchronism motor efficiency optimized adaptive back stepping control research", Electric Machines and Control, vol. 13, pp. 749-753, 2009.

Jing-Li Miao was born in Hebei Province of China in November 1967. She received her doctoral degree of control theory and control engineering from Beijing University of Science and Technology in January 2010. Her major research fields are power electronics and power drives.

She is an associate professor at Hebei University of Engineering in Handan City, Hebei province of China.Two of her papers are: Miao Jing-li, Li Hua-de, Hu Guang-da, Zhao Ren-tao. Efficiency optimization control of induction motors based on adaptive backstepping method[J]. Electric Machines and Control. 2009,13(5):749-753. and Miao Jing-li, Li Hua-de, $\mathrm{Hu}$ Guang-da, Zhao Ren-tao. Maximum ratio of torque to current of induction motor based on predictive functional control[J]. Control and Decision. 2010,25(2):218-222. Her current research interests include power electronics and power drives.

Yuan Huang was born in Hebei Province of China in July 1987 $\mathrm{He}$ received his Bachelor's degree from Hebei University of Engineering in Handan City, Hebei province of China in 2010. $\mathrm{He}$ is now a postgraduate at Hebei University of Engineering. His major research fields are motor drive control and power electronics. 